\title{
La contradicción en materia probatoria, en el marco del proceso penal colombiano
}

The contradiction in evidenciary matters in the framework of the colombian criminal process

Yarleys de Carmen Zabaleta Ortega

Fecha correspondencia:

Recibido: diciembre 21 de 2016.

Revisión: enero 10 de 2017.

Aceptado: marzo 21 de 2017

Forma de citar:

Zabaleta Ortega, Y. (2017). La contradicción en materia probatoria, en el marco del proceso penal colombiano. Rev. CES Derecho., 8(1), 172-190.

Open access

Términos de uso

Licencia creative commons

Ética de publicaciones

Revisión por pares

Gestión por Open Journal System

DOl: http://dx.doi.org/10.21615/cesder.8.1.9

ISSN: 2145-7719

Sobre los autores:

1. Unidad administrativa especializada de gestión de tierras - Universidad de Antioquia.

\section{Comparte}

\section{Resumen}

En el marco de un Estado Social de Derecho, el proceso penal deberá estar investido de unos atributos que le confieran legitimidad y, a la vez, sirvan de control al poder de los Jueces, esos atributos o límites se encuentran englobados en la noción de debido proceso. Dentro de los contenidos del macro principio del debido proceso, encontramos el derecho de contradicción probatoria, el cual se constituye en una de las garantías más importantes dentro del proceso penal, pues este materializa el derecho de defensa y permite el desarrollo de valores tan importantes como la libertad.

El derecho de contradicción probatoria en la fase de juicio oral se convierte en la oportunidad para el procesado de defenderse, de refutar y oponerse a las afirmaciones realizadas por la parte contraria, de aportar elementos que le permitan desvirtuar lo dicho en su contra.

Palabras claves: Debido proceso, derecho de defensa, garantías procesales, prueba.

\section{Abstract}

In the context of a Social State of Law, the criminal process must be invested with attributes that confer legitimacy and, at the same time, serve as a control to the power of Judges, these attributes or limits are encompassed in the notion of due process, within the contents of the macro-principle of due process we find the right of probationary contradiction, which constitutes one of the most important guarantees within the criminal process, since this materializes the right of defense and allows the development of such important values such as freedom.

The right of probationary contradiction in the oral trial stage becomes the opportunity for the defendant to defend himself, to refute and oppose the statements made by the opposing party, to provide elements that allow him to misrepresent what was said against him.

Keywords: Due process, right of defense, procedural guarantees, evidence.

\section{Introducción}

La Constitución Política Colombiana contempla una serie de derechos fundamentales que deberán ser garantizados a todos los habitantes del territorio, y para que estos se protejan y materialicen la misma contempla 
unas garantías procesales que guardan la integridad de dichos derechos. Una de las garantías más importantes contempladas en nuestro ordenamiento jurídico es el debido proceso, y dentro de esa macro garantía encontramos el derecho de contradicción probatoria.

En consecuencia el proceso penal debe darse respetando lo preceptuado en nuestra Constitución acerca del debido proceso y del derecho de contradicción, por tal razón el objeto de este trabajo será determinar si en el marco del proceso penal en materia probatoria se garantiza el derecho de contradicción.

Para el logro de dicho objetivo en primer lugar se realizará una aproximación al principio de contradicción en materia probatoria, nos ubicaremos en el macro principio del debido proceso, y describiremos el contenido y alcance del derecho de contradicción.

En segundo lugar se describirá el proceso penal y se realizara una aproximación a la estructura probatoria del mismo, y finalmente se concluirá describiendo como se evidencia el derecho de contradicción en materia probatoria en el marco del proceso penal colombiano.

\section{Preliminares}

Colombia, de conformidad con la estructura jurídica establecida por la Constitución Política, se erige en un Estado Social de Derecho, personalista y de orientación democrática que, como finalidades, persigue la convivencia pacífica, la consecución de un orden justo y la efectividad de los derechos de los ciudadanos, la Corte Constitucional en la Sentencia C 406 (1992) afirma:

Otro de los pilares del Estado social de derecho se encuentra en el concepto de derecho fundamental. Dos notas esenciales de este concepto lo demuestran. En primer lugar su dimensión objetiva, esto es, su trascendencia del ámbito propio de los derechos individuales hacia todo el aparato n Más aún, el aparato no tiene sentido si no se entiende como mecanismo encaminado a la realización de los derechos. En segundo lugar, y en correspondencia con lo primero, la existencia de la acción de tutela, la cual fue establecida como mecanismo de protección inmediata de los derechos frente a todas las autoridades públicas y con posibilidad de intervención de la Corte Constitucional para una eventual revisión de las decisiones judiciales, que sirva para unificar criterios de interpretación.

Esto indica que el Estado colombiano no solo contempla la existencia de derechos sino de mecanismos para garantizar los mismos, y para regular los conflictos que puedan llegar a generarse.

Por lo anterior, y en el entendido de que los conflictos intersubjetivos de intereses son consustanciales a la convivencia en sociedad, ya que no se puede concebir esta sin diferencias, pues cada ser humano tiene intereses propios que desea asegurar y se hace necesaria una regulación que permita dicha convivencia en sociedad, es entonces que el proceso se constituye en un mecanismo de resolución pacífica y definitiva de conflictos, Alvarado Velloso (2002), afirma:

Si la idea de proceso se vincula histórica y lógicamente a la necesidad de organizar un método de debate dialectico y se recuerda por qué fue menester ello, surge claro que la razón de ser del proceso no puede ser otra cosa que la 
erradicación de la fuerza del grupo social, para asegurar el mantenimiento de la paz y las normas de adecuada convivencia (p.15).

Lo anterior indica que en esa necesidad de convivencia no puede prevalecer el poder del mas fuerte, y por lo tanto se hace necesario la existencia del proceso jurisdiccional, el cual se convierte en una garantía para que los ciudadanos solucionen sus diferencias, con posibilidades de interactuar sin recurrir a la fuerza, ni a la violencia, ya que su conflicto será tramitado ante un tercero imparcial, investido de potestad para decir el derecho de acuerdo a la información presentada por las partes para sustentar su pretensión. En tal sentido se acoge la definición de jurisdicción planteada por Ramírez Agudelo (2007) quien manifiesta:

La Jurisdicción es una función ejercida por un tercero suprapartes, dirigida a lograr paz social por medio del acto de juzgar. Ha de precisarse que la jurisdicción es una función que se ejerce en un método de debate que concreta este último acto jurisdiccional. La jurisdicción permite resolver propiamente una pretensión procesal susceptible de ser resistida, previo agotamiento de un proceso, sin que pueda equiparse con cualquier tipo de resolución judicial como sucede en el evento de la jurisdicción voluntaria (p.10 y 11)

Sin embargo, en el marco de un Estado Social de Derecho, el proceso jurisdiccional deberá estar investido de unos atributos que le confieran legitimidad y, a la vez, sirvan de control al poder de los Jueces. Esos atributos o límites se encuentran englobados en la noción de debido proceso.

La "idea" de debido proceso surge con la Carta Magna de 15 de junio de 1215, en esta Juan Sin Tierra "...se comprometía a respetar los fueros e inmunidades de la nobleza y a no disponer la muerte ni la prisión de los nobles ni la confiscación de sus bienes, mientras aquellos no fuesen juzgados por 'sus iguales" (Valencia Vega, 1988, p. 81). Del derecho ingles la idea del debido proceso pasó a la IV Enmienda de la Constitución Política de los Estados Unidos (1968), donde se estableció:

No se violará el derecho del pueblo a la seguridad en sus personas, hogares, documentos y pertenencias, contra allanamientos e incautaciones fuera de lo razonable, y no se emitirá ningún Mandamiento judicial para el efecto, si no es en virtud de causa probable, respaldada por Juramento o promesa, y con la descripción en detalle del lugar que habrá de ser allanado y de las personas o efectos que serán objeto de detención o incautación.

Además, el mencionado derecho se fue desarrollando y consolidando en la jurisprudencia y en la cultura jurídica de los Estados Unidos, e igualmente fue siendo replicado en toda América, y consagrado en cada Constitución Política.

Este derecho fundamental cobra mucha importancia en un Estado Constitucional y Democrático, ya que se convierte en un freno a la arbitrariedad y garantiza la convivencia pacífica, pues mediante este se erradica completamente la fuerza del poder ilegitimo y se permite que las partes en conflicto solucionen sus diferencias, o que los sujetos que contravengan la ley, sean sancionados, pero, a través de un Juicio imparcial, donde un tercero sea quien medie, diga o interprete la Ley.

El Constituyente de 1991 consagró el derecho al debido proceso en el artículo 29 de la carta política, afirmando que este se aplicará a toda clase de actuaciones judi- 
ciales y administrativas, de igual forma este derecho ha sido desarrollado jurisprudencialmente por la Corte Constitucional en la Sentencia T 001 de 1993 como, "el conjunto de garantías que protegen al ciudadano sometido a cualquier proceso, que le aseguran a lo largo del mismo una recta y cumplida administración de justicia, la seguridad jurídica y la fundamentación de las resoluciones judiciales conforme a derecho". Por su parte Bernal Pulido (2005) expreso,

Este esquema, entonces, lo debido en general, y el derecho en particular, no dependen de un único concepto de justicia material, impuesto por la visión de la autoridad, sino del diálogo entre interlocutores que exponen sus cosmovisiones y sus necesidades mediante procedimientos que los incluyen y les ofrecen la garantía de poder expresarse sin más cortapisas que aquellas que se derivan del respeto de los derechos de los demás (p.335).

Pues bien en un Estado Social de Derecho, el debido proceso debe ser considerado como garantía, pues este sirve "como un mecanismo para la protección de otros derechos fundamentales en el Estado democrático" (Bernal Pulido, 2005, p.337). También afirma Agudelo Ramírez (2005):

El caso del proceso jurisdiccional, el debido proceso incorpora la exigencia del cumplimiento de requisitos y condiciones formales que, en términos de racionalidad práctica, posibilitan la consecución de metas concretas como la vigencia de un orden social justo que tenga por fundamento la dignidad humana (p.5).

Dentro de los contenidos del macro principio del debido proceso se encuentra el principio de contradicción, el cual se constituye en una de las garantías más importante dentro del proceso penal, en términos generales se entiende la contradicción y bilateralidad como la oportunidad de tomar posición y pronunciarse sobre pretensiones y manifestaciones de parte contraria, el carácter participativo de la justicia, la bilateralidad de la audiencia no es más que un elemento de garantía constitucional.

En virtud del derecho de contradicción el proceso debe desarrollarse de tal forma que cada una de las partes tenga oportunidad razonable de tomar posición, de pronunciarse y de contradecir las afirmaciones, pretensiones o pruebas presentadas por la contraparte, se debe brindar oportunidad igual a las partes de participar efectivamente en la relación dialéctica, en la actividad de administración de justicia, este método de igual oportunidad de acción y de contradicción es el que debe seguirse para buscar la verdad material en el proceso.

De acuerdo con Agudelo Ramírez (2005) el debido proceso es:

... un derecho fundamental que reclama de procedimientos pluralistas y ampliamente participativos, en los que se asegure la igualdad y un debate que permita la defensa de todos sus participantes. Dichos procedimientos, en los que sólo podrá decidirse de fondo de conformidad con el derecho sustancial preexistente, deberán ser desarrollados de conformidad con las formas preestablecidas en el ordenamiento y estar dirigidos por terceros supraordenados, exclusivos, naturales, imparciales e independientes (p.7).

El derecho de contradicción se materializa en la posibilidad de participar en el proceso, de oponerse, de refutar las afirmaciones de la parte contraria, "el derecho a ser oído implica la posibilidad de otorgar a las partes procesales idénticas oportu- 
nidades de defensa, no pudiendo el Juez emitir una determinada decisión cuando no se ha dado la oportunidad de ser escuchado en un término razonable" (Aqudelo Ramírez, 2005, p.9).

Lo esbozado indica que el proceso penal en Colombia debe darse con observancia de un debido proceso, en especial asegurando la contradicción probatoria, pues solo en un juicio contradictorio, donde las partes interactúen es posible llegar a la verdad y consecuentemente a una sentencia justa, que satisfaga las expectativas de las partes.

El uso de la prueba se encuentra presente en todas las esferas de la vida, puesto que cotidianamente, se busca justificar la realización de determinadas conductas o actividades, a través de diversos instrumentos, o discursos, "la noción de prueba está presente, en todas las manifestaciones de la vida humana. De ahí que exista una noción ordinaria o vulgar de la prueba, al lado de una noción técnica. Y que esta varié según la clase de actividad o ciencia que se aplique", (Devis Echandía, 2012, p.9), "el concepto de prueba se encuentra fuera del derecho y es instrumento indispensable, para cualquiera que haga ya no derecho sino historia". (Carnelutti, 1955, p.4).

Por otra parte, Devis Echandía (2012) afirma:

En derecho la prueba se utiliza principalmente para convencer a otros (a los Jueces, funcionarios de policía, o administrativos, cuando se aduce en un proceso o en ciertas diligencias, también a particulares, como sucede en asuntos del estado civil, o en titulación de bienes para su comercio, en relaciones de vecindad o con un fin de prevención de litigios y de garantía. (p.10)

Dentro de las características del derecho a probar o a la prueba, entendido como derecho fundamental, se encuentran: 1) inherencia a la persona humana, 2) aplicación directa, 3) protección reforzada (exigibilidad por vía de acción tutela y protección por medio de Leyes Estatutarias).

Es innegable el índice de aplicabilidad de una institución tan importante como la prueba, pues es el uso de esta es la que permite realmente que los sujetos de determinado proceso presenten sus argumentos y hagan valer los elementos que permitan contradecir las afirmaciones que se hagan en su contra, así pues debe entenderse por prueba "el conjunto de reglas que regulan la admisión, producción, asunción, y valoración de los diversos medios que pueden emplearse para llevar al Juez a la convicción sobre los hechos que interesan al proceso" (Echandía, 2012, p.15). Esta definición es asumida también por Ruiz Jaramillo (2007) quien además plantea que “...la prueba es el elemento conector entre el derecho procesal y el sustancial, es el puente e entre ellos" (p.188), pues es a través de esa garantía fundamental que se materializan los derechos que se debaten en un proceso, ya que el Juez no puede conocer la verdad, ni formar su convicción sin que medie la prueba.

De acuerdo a lo expuesto por Ruiz Jaramillo (2007, p.204) existe en el ordenamiento jurídico un derecho a la prueba que permite la efectividad de los derechos y que éstos no se hagan nugatorios.

El referido autor define ese derecho como la posición jurídica iusfundamental de exigir al estado la obtención (aseguramiento, admisión, decreto y práctica de prueba) y valoración de la prueba. 
Este derecho tiene dos dimensiones, una objetiva y otra subjetiva, según la dimensión subjetiva, este derecho posibilita exigir un hacer o no hacer (en términos de prueba) al obligado (Juez o quien haga sus veces). Mientras que la esfera objetiva se erige en un criterio de validez formal y material de la regulación sobre las pruebas. "En este sentido los derechos fundamentales asumen, en el conjunto normativo, el carácter de principios, como punto referencial del ordenamiento" (Ruiz Jaramillo, 2006, p.5).

Pues bien la dimensión objetiva de la prueba permite que se materialicen principios fundamentales de la misma, dentro de ellos la contradicción, y que se haga exigible que el Juez propicie las condiciones para que se respeten las condiciones procesales. Ruiz Jaramillo (2007) afirma: “...además, mediante la acción de tutela y otros mecanismos constitucionales, la persona puede exigirle al Juez constitucional el control de todos los procedimientos y contenidos de las decisiones emanadas por las autoridades públicas e incluso de particulares que puedan afectar sus derechos fundamentales" (p.186)

Por su parte Ruiz Jaramillo, citando a Picó I Junoy (1996) indica:

El carácter subjetivo del derecho a la prueba se manifiesta en que su ejercicio demanda la voluntad de una de las partes, quedando a su arbitrio la posibilidad de proponer el medio probatorio que pretende para que sea admitido, practicado y valorado judicialmente; este derecho puede radicar en un sujeto, en una persona u órgano. (p.20)

De acuerdo con lo expuesto se puede afirmar que siendo la prueba una garantía fundamental que permite alcanzar la convicción acerca de los hechos que se debaten, y obtener la verdad que se persigue, es necesario que esta se materialice a través de una serie de principios del derecho probatorio, los cuales le dan contenido, y eficacia. Uno de esos principios es la comunidad de la prueba, según el cual "Los efectos de la prueba los decide de forma racional el Juez, con exclusión de los intereses u objetivos de las partes con la prueba" (Ruiz Jaramillo, s.f, p.2), lo cual indica que la prueba no es de las partes, es del proceso, pues con ella se busca que el Juez adquiera convicción, por lo tanto las partes no podrán disponer de las mismas, y será el Juez quien decida sobre la veracidad de estas.

De igual forma la prueba es necesaria dentro de proceso, ya que el Juez no podrá valerse para decidir en el proceso del conocimiento obtenido por este fuera de él, toda vez que la sentencia debe ser consecuencia de lo debatido y aprobado, la certeza de los hechos el Juez la debe adquirir de los elementos que le sean allegados, por ningún motivo podrá valerse de su conocimiento privado pues violaría el debido proceso. "El principio de la necesidad de la prueba hace parte íntegra del derecho a la prueba, pues este último no tendría un contenido serio si no incluyera la exigencia de que el Juez base su decisión en pruebas", (Ruiz Jaramillo, s.f, p.5). Este principio, además garantiza la seguridad jurídica de que el Juez decidirá conforme a lo que se haya probado y no conforme a su arbitrio.

Los elementos o medios de prueba que se alleguen al proceso conforman un todo, que el Juez tendrá que valorar, sin importar a cuál de las partes pueda beneficiar, pues como se dijo las pruebas sirven al proceso, por lo tanto el Juez tendrá que apreciarlas y valorarlas todas, como una unidad. 
Otro de los principios importantes del derecho a la prueba es el principio de publicidad, este adquiere especial relevancia, pues se constituye en una de las garantías más importantes para que el procesado ejerza su derecho de defensa y contradicción, no podría pensarse el derecho a la prueba sin el principio de publicidad, pues si la primera no se publica seria inexistente el derecho de contradicción de la prueba.

La publicidad además es un contrapeso a la arbitrariedad pues permite que la sociedad en general conozca los actos de la administración de justicia y por consiguiente los controle y los controvierta, este principio permite que se active el principio de contradicción, pues abre la posibilidad para que las partes luego de haber conocido lo que se aduce en su contra aporten elementos que desvirtúen las afirmaciones hechas en su contra, y de refutar los argumentos de las decisiones judiciales que le afecten, "Este principio opera en todos los momentos de la actividad probatoria: en la obtención de la prueba y en la valoración; lo cual significa que los operadores jurídicos pueden controvertir el decreto, la práctica y la valoración probatoria" (Ruiz, s.f. p. 14).

El Derecho de Contradicción de la Prueba, se puede definir, como la facultad que tiene toda persona de controvertir las pruebas que se a aduzcan en su contra, este derecho es el que garantiza que se dé un procedimiento justo que además este diseñado de tal forma que los individuos les sea otorgada la audiencia abierta ante un Juez Imparcial, lo cual es fundamental en la garantía constitucional del debido proceso, en todo proceso penal debe asegurársele al procesado la efectiva oportunidad de ser escuchado y además se le debe dar un tiempo suficiente para que tenga oportunidad objetiva de presentar su objeciones.

Hoyos (1993) expone,

La garantía constitucional del debido proceso es una institución instrumental en virtud de la cual debe asegurarse a las partes en todo proceso legalmente establecido y que se desarrolle sin dilaciones injustificadas, oportunidad razonable de ser oídas por un tribunal competente, predeterminado por la ley, independiente e imparcial, de pronunciarse respecto de tenciones y manifestaciones de la parte contraria, de aportar pruebas licitas relacionadas con el objeto del proceso (p.54).

\section{Aproximación al principio de contradicción en materia probatoria}

El principio de la contradicción es uno de los principios más importantes que comporta el derecho a la prueba, pues este materializa el derecho de defensa y permite el desarrollo de valores tan importantes como la libertad, la Corte Constitucional en Sentencia C 553 (2000), afirma. "Se entiende por "controversia de la prueba" es la posibilidad que tiene el sindicado o imputado de pronunciarse sobre el valor, el contenido y los elementos internos y externos del material recaudado y con base en ello sustentar la argumentación de la defensa".

El principio de Contradicción ha sido desarrollado en varios instrumentos internacionales ratificados por Colombia, que hacen parte del Bloque de Constitucionalidad. La Declaración Universal de Derechos Humanos (1948) consagró:

Toda persona acusada de delito tiene derecho a que se presuma su inocencia mientras no se pruebe su culpabilidad, conforme a la ley y en juicio público en el que se le hayan asegurado todas las garantías necesarias para su defensa. 


\section{Definición}

El derecho de contradicción probatoria no es más que la posibilidad de las partes de defenderse, de refutar y oponerse a las afirmaciones realizadas por la parte contraria, de aportar elementos que le permitan desvirtuar lo dicho en su contra, dicha posibilidad exige que se den ciertas garantías probatorias que son el desarrollo del debido proceso consagrado en nuestra carta política, la Corte Constitucional en Sentencia C 1270 (2000), en cuanto al derecho a la prueba esbozó que se debe dar los siguientes:

i) El derecho para presentarlas y solicitarlas; ii) el derecho para controvertir las pruebas que se presenten en su contra; iii) el derecho a la publicidad de la prueba, pues de esta manera se asegura el derecho de contradicción; iv) el derecho a la regularidad de la prueba, esto es, observando las reglas del debido proceso, siendo nula de pleno derecho la obtenida con violación de éste; v) el derecho a que de oficio se practiquen las pruebas que resulten necesarias para asegurar el principio de realización y efectividad de los derechos; y vi) el derecho a que se evalúen por el juzgador las pruebas incorporadas al proceso.

De igual forma afirma la Corte Constitucional Sentencia C 790 (2006);

El derecho de contradicción apunta a dos fenómenos distintos. De una parte, a la posibilidad de oponer pruebas a aquellas presentadas en su contra. Desde esta perspectiva, el derecho de contradicción aparece como un mecanismo directo de defensa, dirigido a que las razones propias sean presentadas y consideradas en el proceso. Su vulneración se presentaría cuando se impide o niega la práctica de pruebas pertinentes, conducentes y oportunas en el proceso. Por otro lado, se refiere a la facultad que tiene la persona para (i) participar efectivamente en la producción de la prueba, por ejemplo interrogando a los testigos presentados por la otra parte o por el funcionario investigador y (ii) exponer sus argumentos en torno a lo que prueban los medios de prueba.

Así las cosas la contradicción probatoria se puede entender como la participación de las partes en cada una de las fases de la actividad probatoria, y en la construcción argumentativa de la verdad, este es un derecho que emana del derecho constitucional y permite que la defensa se haga efectiva en cada proceso, donde contra quien se dirige una pretensión pueda hacer uso de los medios que sean necesarios para su defensa.

\section{Contenido del derecho de contradicción probatoria}

El derecho de contradicción probatoria hace posible que el procesado pueda defenderse en el proceso penal, ya que permite que este tenga igualdad de derechos con quien lo acusa, y le da la posibilidad de controvertir algunos aspectos de la obtención de la prueba y la valoración de la prueba, este puede controvertir u oponerse a la solicitud de prueba, se puede realizar una oposición al decreto de prueba a la práctica de prueba y a la valoración de las mismas, esto solo es posible en un espacio de bilateralidad.

Es tan importante el derecho de contradicción probatoria que su vulneración da lugar a un defecto factico que es susceptible de ataque por vía de recurso extraordinario de casación y por acción de tutela. 


\section{Alcance del derecho de contradicción probatoria}

La prueba es la que le da sentido al proceso penal, pues para llegar a la verdad es necesario que las mismas seas aportadas por las partes, el alcance de la contradicción se encuentra en la vocación que tiene este derecho para convertirse en un arma para defenderse y a la vez para atacar, pues a través de la contradicción probatoria se logra; establecer la verdad y llevar al Juez la convicción necesaria para que tome una decisión justa.

\section{Límites al derecho de contradicción probatoria}

La Corte Constitucional en Sentencia C 371 (2011) recuerda que esa corporación,

...ha admitido que algunas garantías procesales, -y entre ellas el derecho de defensa y contradicción- no son absolutas y pueden ser limitadas por el legislador, siempre que no se vea afectado su núcleo esencial, la limitación responda a criterios de razonabilidad y proporcionalidad, y no se desconozcan otros derechos fundamentales, como puede ser el derecho a la igualdad.

Lo anterior indica que el derecho de contradicción probatoria puede ser limitado en busca de que se efectivicen otras garantías dentro del proceso, tales como la celeridad. La Corte Constitucional en Sentencia C 371 (2011) destaca:

(...) Si los derechos del procesado - como el derecho de defensa - tuvieren primacía absoluta, no podría establecerse un término definitivo para acometer la defensa, ni restringirse la oportunidad para practicar o controvertir las pruebas, ni negarse la práctica de pruebas inconducentes cuando hubieren sido solicitadas por el procesado, etc. Predicar la supremacía irresistible del derecho de defensa equivaldría, en suma, a someter al proceso a las decisiones del procesado, el proceso penal en Colombia es un proceso de partes, es lógico que se establezcan límites que permitan además de la celeridad la igualdad procesal.

De igual forma el derecho a la contradicción probatoria se limita por criterios de pertinencia y necesidad, es decir no es posible practicar todas las pruebas que las partes quieran proponer, pues las mismas deben tener relación con el objeto del proceso, y ser necesarias para llegar a la verdad, pues no tendría sentido por ejemplo practicar pruebas que pretendan probar hechos que no necesitan prueba.

Si bien es cierto el derecho de contradicción probatoria debe ser garantizando en todas las etapas del proceso penal y en especial en el juicio oral, es válido que este tenga restricciones, que permitan armonizar el mismo, y en consecuencia la materialización de principios tan importantes como la celeridad, ya que las partes y el Juez estarán obligados a respetar términos que se constituyen en una garantía para que no se produzcan dilaciones injustificadas. Además es lógico que las pruebas admitidas sean las pertinentes, pues si el derecho de contradicción de la prueba fuera absoluto las partes podrían aprovechar el mismo para pedir la práctica de pruebas innecesarias y se desvirtuaría con ello el objeto del proceso que es llegar a la verdad.

Concretamente el derecho de contradicción en el juicio oral se restringe mediante el establecimiento de términos para la práctica de las pruebas, y en las condiciones para la admisibilidad de los medios de prueba, los cuales deben obedecer a criterios de pertinencia y necesidad. 


\section{Relación con el principio de publicidad}

Puede afirmarse que el derecho de contradicción de la prueba se desarrolla a partir del derecho a la publicidad de la prueba, el principio de contradicción y el principio de publicidad hacen parte del derecho de defensa y del macro derecho a un debido proceso, estos se interrelacionan y se complementan de tal forma que no puede haber contradicción sin publicidad. La Corte Constitucional en Sentencia C 038 (1996) afirmo "toda persona tiene derecho, en condiciones de plena igualdad, a ser oída públicamente y con justicia por un tribunal independiente e imparcial", dicho derecho solo es posible cuando este tiene conocimiento de que contra este e lleva a cabo algún tipo de proceso. En el mismo sentido se pronunció la mencionada Corte Constitucional en sentencia SU 062 (2001), así:

La publicidad como principio constitucional que informa el ejercicio del poder público, se respeta cuando se logra mantener como regla general y siempre que la excepción, contenida en la ley, sea razonable y ajustada a un fin constitucionalmente admisible. La medida exceptiva de la publicidad, igualmente, deberá analizarse en términos de razonabilidad y proporcionalidad, como quiera que ella afecta, según se ha anotado, un conjunto de derechos fundamentales.

Esto indica que la regla es que en nuestro sistema judicial se garantice el derecho a la publicidad, con más razón en el proceso penal, pues en este están en juego derechos tan importantes y sagrados como la libertad, entonces siempre se deben conocer las actuaciones judiciales para poder controvertirlas.

Pues bien la contradicción de la prueba se deriva del principio de publicidad, ya que la única forma de oponerse a la prueba es conociéndola, por lo que el sujeto del proceso penal debe estar informado durante el mismo de las actuaciones realizadas, para así efectivizar adecuadamente su derecho de contradicción probatoria.

Por lo anterior en cuanto al derecho a la publicidad se puede decir que este resulta esencial para que se materialice la contradicción, pues el principio de publicidad garantiza que todas las actuaciones se realicen sean de cara a las partes, y a quienes tengan interés en él, en este sentido es preciso decir que la publicidad es requisito fundamental para que se dé la contradicción, lo cual se constituye en una garantía para evitar la desigualdad entre las partes.

\section{Regulación en Colombia}

El principio de contradicción probatoria está consagrado en el artículo 29 de nuestra Constitución Política (1991), donde se establece la garantía fundamental del debido proceso y en cuanto a la contradicción probatoria afirma:

Quien sea sindicado tiene derecho a la defensa y a la asistencia de un abogado escogido por él, o de oficio, durante la investigación y el juzgamiento; a un debido proceso público sin dilaciones injustificadas; a presentar pruebas y a controvertir las que se alleguen en su contra; a impugnar la sentencia condenatoria, y a no ser juzgado dos veces por el mismo hecho.

Dicho principio también tiene íntima relación con el derecho a la a la igualdad regulado en el artículo 13 de la carta política, en el sentido de que todas las personas tienen los mismos derechos y oportunidades, esto podemos predicarlo del proceso penal, pues el procesado tiene derecho a participar en el mismo en condiciones de igualdad. 
De igual forma el derecho de contradicción probatoria se encuentra regulado en el artículo 15 de la ley 906 de 2004, en el cual se deja claro la posibilidad que tienen las partes de conocer y controvertir las pruebas, así como a intervenir en su formación, tanto las que sean producidas o incorporadas en el juicio, además los artículos 344,356 y 374 del mencionado estatuto regulan la oportunidad procesal para que la Fiscalía y la defensa efectúen el descubrimiento probatorio que permita a la contraparte ejercer a cabalidad la contradicción.

\section{Contradicción y derecho a la prueba}

El principio de contradicción probatoria es una concreción del principio procesal de contradicción, la contradicción probatoria tiene una relación íntima con el derecho de contradicción, hasta el punto de que no se entiende materializado el derecho de defensa sin contradicción.

La contradicción probatoria puede entenderse como la posibilidad de proponer todos los medios de prueba útiles para la confirmación de los hechos en sede procesal, es decir el procesado podrá presentar todas las pruebas con las que pueda defender su teoría de verdad, además este tendrá la posibilidad de discutir la prueba allegada en su contra, si el objeto de la misma es llegar a la verdad, es apenas necesario que contra quien se aduzca la prueba tenga la oportunidad de controvertirla, ya sea cuestionándola, o refutándola, también el derecho de contradicción de la prueba se materializa en la posibilidad de las partes de participar en la práctica de la prueba, ya que la misma se practicara en juicio, oral y contradictorio.

El derecho a la prueba permite además que el procesado pueda proponer las pruebas que considere que sean pertinentes, y además tiene la posibilidad de impugnar las que considere ilegales, o impertinentes, en todo caso tendrá la oportunidad de pronunciarse frente a la prueba, exponiendo sus argumentos y análisis.

\section{Aproximación a la estructura probatoria del proceso penal regido bajo la Ley 906 de 2004}

Estructura del proceso penal colombiano

El sistema penal colombiano, regulado por la Ley 906 de 2004 no acoge un sistema penal acusatorio puro, al respecto la Corte Constitucional en Sentencia C 591 (2005) manifestó: en la interpretación del nuevo Código de Procedimiento Penal, se debe partir de la premisa de que la estructura del mismo adoptada mediante el Acto Legislativo 03 de Estructura del proceso penal acusatorio no corresponde exactamente a ningún modelo puro. La anterior aseveración encuentra respaldo adelantando un parangón entre los modelos acusatorios americano y continental europeo, que resalta las características propias que presenta nuestro sistema procesal penal, sistemas extranjeros que podrán ser tenidos en cuenta solo como un elemento de juicio, de apoyo o de conocimiento para la comprensión del nuevo sistema procesal penal.

Por su parte la Corte Suprema de Justicia en Sentencia 26468 (2007) resaltó:

El modelo de justicia bajo el régimen acusatorio insertado en la realidad procesal nuestra parece tener un predominante origen en aquellos sistemas continentales europeos, como que sigue siendo ostensible el predominio del principio de legalidad ejercido por el Juez, que se hace manifiesto en la determinación del cambio de radi- 
cación de un proceso, la definición de la conexidad y de competencia, el decreto de medidas cautelares sobre bienes, el control de las medidas asegurativas y sobre la determinación de la Fiscalía de dar aplicación al principio de oportunidad, o sobre el escrito de acusación, mediando en el descubrimiento de los elementos probatorios y las pruebas, o interrogando a los testigos, o en relación con la aprobación de los preacuerdos y negociaciones celebrados entre Fiscalía y acusado que puede rechazar si advierte vulneración de "garantías fundamentales.

Además de decidir sobre la pertinencia y admisibilidad de pruebas que se han de llevar al juicio, asistiéndole inclusive la posibilidad al Juez de control de garantías -no así al de conocimiento-, de decretar pruebas de oficio en defensa de los derechos y garantías.

El proceso penal en Colombia, regulado por la Ley 906 de 2004, se divide en tres etapas: indagación, investigación y juzgamiento. La indagación tal como lo establecen los artículos 200 y 201 de la ley 906 (2004), inicia con la noticia criminal; esta puede nacer a partir de una denuncia, querella, petición de parte o de oficio, en esta primera etapa la Fiscalía a través de la policía judicial se encarga de recolectar elementos materiales probatorios o evidencia física, con los cuales pretenderá demostrar que ocurrió una conducta punible, e individualizara las personas que posiblemente hayan cometido dicha conducta punible.

La etapa de investigación tal como lo contempla la Ley 906 (2004, artículos 286, 287, y 288) inicia con la formulación de la imputación, de acuerdo con lo establecido en esta audiencia la Fiscalía comunica al procesado que se adelanta una investigación penal en su contra, para que este pueda ejercer su derecho de defensa y contradicción, informándole cuales son los hechos por los que se investiga, encuadrando la conducta jurídicamente.

La tercera y última etapa del proceso penal colombiano es la de juzgamiento; esta etapa inicia con la audiencia de formulación de acusación; en esta el Fiscal de la causa ante el Juez de conocimiento relata los hechos por los cuales se investiga al procesado y por los cuales deberá llevarse a cabo un juicio, en esta audiencia se da la oportunidad para que se formulen recusaciones o impedimentos, incompetencias y nulidades (Ley 906, 2004, artículos 338, 339).

Esta audiencia es muy importante porque es el momento para que la Fiscalía formule su acusación, haciendo un relato de los hechos por los que el acusado será llevado a juicio, en esta audiencia la Fiscalía descubrirá los elementos materiales probatorios que pretenda hacer valer en el juicio oral (Ley 906, 2004, artículo 344).

En cuanto al descubrimiento probatorio la Corte Suprema de Justicia (2012) manifestó:

El descubrimiento probatorio constituye parte de la esencial del sistema adversarial consagrado en nuestro ordenamiento jurídico, y por tal motivo la Fiscalía y la defensa deben suministrar, exhibir o poner a disposición todos los elementos materiales probatorios y evidencia física que posean como resultado de sus averiguaciones y que pretendan sean decretadas como pruebas y practicadas en el juicio oral en sustento de sus argumentaciones, permitiendo de esa manera que la contraparte conozca oportunamente cuáles son los instrumentos de prueba sobre los cuales el adversario fundará su teoría del caso y, de ese modo, elaborar las distintas estrategias propias de la labor encomendada en procura del éxito de sus pretensiones. 
Posterior a la audiencia de formulación de acusación tiene lugar la audiencia preparatoria, en ésta, Fiscalía y defensa enuncian las pruebas que llevaran al juicio para hacerlas valer y manifiestan si tienen interés en hacer estipulaciones probatorias. De acuerdo con lo tramitado en esta audiencia el Juez decreta las pruebas que se practicaran en juicio y fija la fecha para el mismo. La Corte suprema de Justicia en Auto AP3136 (2014) indica:

El correcto y oportuno descubrimiento probatorio constituye condición sine qua non para la admisibilidad de la prueba porque, según el artículo 346 ibídem, el Juez tiene la obligación de rechazar todas aquellas evidencias o elementos probatorios respecto de los cuales no se haya cumplido el deber de revelar información durante el procedimiento de descubrimiento.

Lo anterior indica que se hace indispensable que Fiscalía y defensa cumplan con la obligación de realizar el descubrimiento probatorio, para que sea efectivo el derecho de contradicción y de no cumplir con esta obligación, la sanción será que dicha prueba no sea practicada en el juicio oral.

Pues bien la audiencia preparatoria tiene gran importancia en materia de contradicción probatoria, como viene dicho en ella se pueden realizar observaciones sobre el descubrimiento probatorio de la Fiscalía, en los términos de los artículos 344, 345 y 346 de la ley 906 (2004), y además en el evento de que el descubrimiento no se haya realizado de manera completa y oportuna, se puede solicitar la exclusión de esos elementos materiales probatorios. De igual forma se puede realizar la oposición al decreto de pruebas y se pueden interponer recursos en contra del auto que decreta o no pruebas.

Posteriormente de acuerdo con lo preceptuado en los artículos 366 y 367 de la Ley 906 (2004) en la etapa de juzgamiento se da la audiencia de juicio oral, esta se instalara en día y hora señalados en la audiencia preparatoria, el Juez instalará el juicio oral, previa verificación de la presencia de las partes, en esta la Fiscalía expone su teoría del caso, y la defensa si lo desea, y seguidamente se procede a la práctica de pruebas, después de haber practicado las pruebas, Fiscalía y defensa expondrán sus alegatos finales y el Juez dará el sentido del fallo.

\section{Relevancia probatoria de las audiencias de formulación de Acusación, preparatoria y de juicio oral}

\section{Audiencia de formulación de acusación}

La audiencia de formulación de acusación es la oportunidad procesal que contempla la ley 906 de 2004 para que la Fiscalía exponga los elementos de juicio, las evidencias y el material fáctico que pretende aducir como pruebas en el juicio oral a fin de demostrar que el procesado es culpable de una conducta punible y desvirtuar la presunción de inocencia del mismo.

En esta audiencia, el derecho de defensa inicia con la posibilidad que tiene la defensa para proponer objeciones al escrito de acusación presentado por la Fiscalía, si no reúne los requisitos establecidos en el artículo 337 de la ley 906 de 2004, para que el Fiscal lo aclare, adicione o corrija de inmediato.

Además en esta audiencia la defensa puede pedir el descubrimiento de un elemento 
material probatorio especifico de que tenga conocimiento, esta posibilidad garantiza el derecho de contradicción probatoria, porque si bien es cierto que el Fiscal tiene la obligación de suministrar en el escrito de acusación todos los elementos materiales o evidencia física que tenga en su poder, por un motivo u otro podría omitir tal obligación, por lo que la norma contemplo esta garantía que permite que todas las pruebas sean conocidas por el procesado.

Posteriormente se da el descubrimiento probatorio por parte de la Fiscalía, este es un acto procesal muy importante y trascendental a través del cual la Fiscalía informa al acusado acerca de cuáles son los elementos materiales probatorios y evidencia física que pretenden hacer valer en el juicio, aquí tiene la obligación de descubrir absolutamente todos los documentos que tiene en su poder o que llevara al juicio, también manifestara con que testigos o peritos introducirá dichos elementos probatorios, también deberá informar con que testigos cuenta, así como las entrevistas, y declaraciones que hubiere practicado a los testigos, y los informes de policía o informes técnicos obtenidos durante la investigación.

Durante el descubrimiento probatorio por parte de la Fiscalía el procesado a través de su abogado defensor estará atento a los elementos y evidencias que el Fiscal exponga, a fin de realizar observaciones sobre el descubrimiento probatorio de la Fiscalía, el cual debe ser congruente con los elementos materiales probatorios descubiertos en el escrito de acusación, y con las solicitudes probatorias realizadas por las partes en la preparatoria y las pruebas decretadas y las pruebas practicadas en audiencia de juicio oral.

\section{Audiencia preparatoria}

La audiencia preparatoria tiene como fin último la fijación de las pruebas que se harán valer en el juicio oral y el señalamiento de la fecha de iniciación del juicio, en esta audiencia se verifica el descubrimiento probatorio hecho por la Fiscalía, es en este estadio donde realmente se activa el derecho de contradicción, ya que el procesado a través de su abogado defensor podrá pronunciarse acerca de la legalidad, licitud, admisibilidad, conducencia y pertinencia de cada uno de los medios que la Fiscalía pretenda introducir al juicio oral, una vez presentados los medios de prueba se activa el derecho de contradicción probatoria para el procesado, quien podrá pedir la exclusión o rechazo de un medio probatorio.

De igual forma se realiza el descubrimiento probatorio por parte de la defensa, quien aprovechara esta oportunidad procesal para solicitar todas las pruebas que le permitan desvirtuar lo aducido por la Fiscalía, y sustentar su teoría del caso si así lo desea, aquí podrá hacer uso de la contradicción probatoria, incorporando elementos que le permitan desvirtuar lo expuesto por la Fiscalía.

Como ya se dijo el descubrimiento probatorio garantiza que se concrete el principio procesal de contradicción probatoria, ya que conociendo que tiene la contraparte en su poder se puede preparar de manera adecuada el ejercicio de la defensa en materia probatoria.

La Corte Suprema de Justicia (2007) ha dicho que la Fiscalía cumple con el deber de suministrar elementos probatorios así:

i) Imprescindiblemente y en todos los casos, "descubriéndolos", esto es, informando a la defensa, en las oportunidades procesales antedichas, con plena lealtad y con 
sujeción al principio de objetividad, sobre la existencia, naturaleza y ubicación de todos y cada uno de los elementos probatorios y evidencias; máxime si la Fiscalía va a utilizarlos para sustentar la acusación y si podrían generar efectos favorables para el acusado.

ii) Entregándolos físicamente cuando ello sea racional y materialmente posible, como con resultados de un informe pericial o policial, la copia de algunos documentos o algunos elementos o muestras de los mismos.

iii) Facilitando a la defensa el acceso real a las evidencias, elementos y medios probatorios en el lugar donde se encuentren, o dejándolos a su alcance, si fuere el caso, de modo que pueda conocerlos a cabalidad, estudiarlos, obtenerlos en la medida de lo racionalmente posible y derivar sus propias conclusiones, de cara a los fines de la gestión defensiva.

El correcto y completo descubrimiento probatorio condiciona la admisibilidad del medio de prueba, pues si tal descubrimiento no se hiciera de manera adecuada, dichos elementos no podrían ser usados como pruebas durante el juicio oral, de acuerdo con lo preceptuado en el artículo 356 del código de procedimiento penal y el Juez estaría en la obligación de rechazar todas las evidencias físicas o elementos probatorios no descubiertos.

Una manera de garantizar el derecho de contradicción probatoria es interponiendo recurso de apelación en contra de las decisiones que decretan pruebas, (posibilidad que ha surgido por vía jurisprudencial), las que excluyen, rechazan o niegan la práctica de pruebas. El artículo 363 de la ley 906 de 2004 consagra como motivo de suspensión de la audiencia preparatoria el trámite de la apelación de las providencias relacionadas con pruebas.

\section{Audiencia de juicio oral}

La etapa del Juicio Oral es la más importante dentro del proceso penal en materia de contradicción probatoria, dicho juicio se rige por los principios de publicidad, oralidad, inmediación de las pruebas, concentración y contradicción. Una vez se realiza la instalación de la audiencia de juicio oral se le da la oportunidad a la Fiscalía, para que presente alegato de apertura, en esta la Fiscalía describirá los hechos que son jurídicamente relevantes, y encuadrara jurídicamente la conducta del acusado, igualmente presentara la relación de las pruebas con las que buscara demostrar y convencer al Juez de que el acusado es responsable de la conducta que se investiga, adicionalmente, este deberá relacionar el soporte probatorio con el que cuenta para demostrar más allá de toda duda que el procesado es culpable.

De la misma forma la defensa tendrá la oportunidad de presentar su alegato inicial si desea hacerlo, y seguidamente se procederá a la práctica de pruebas de acuerdo al orden señalado en la audiencia preparatoria.

En el juicio oral Fiscalía y defensa se encuentran en condiciones de igualdad, teniendo ambas partes la posibilidad de contradecir las afirmaciones de la contraparte, de confrontar las pruebas que la otra parte aduzca, en materia probatoria también es posible contradecir la prueba cuestionando la misma.

Otro aspecto importante que se da en el juicio oral es el interrogatorio de los testigos, y la contradicción probatoria se materializa en la posibilidad de la contraparte de poder contrainterrogarlos, y a través de dicho contrainterrogatorio desvirtuar 
lo dicho por estos. De igual forma el principio de contradicción se materializa en la oportunidad de utilizar el interrogatorio cruzado del testigo contemplado en el artículo 391 de la ley 906 (2004), a través de este la parte distinta a quien solicito el testigo podrá hacerle preguntas que le permitan defenderse, o demostrar su teoría.

La contradicción va más allá de la participación en la práctica de las pruebas, la contradicción probatoria se materializa en la posibilidad de pedir pruebas, y de desvirtuar las de la otra parte, y de realizar un análisis de la información aportada al proceso, la defensa podrá analizar si las pruebas se contradicen unas con otras, si fueron legalmente obtenidas, o si son suficientes para lograr el convencimiento del Juez.

También se puede participar en el debate probatorio presentando objeciones durante los interrogatorios a los testigos, siempre que quien interrogue viole las reglas para el interrogatorio, las objeciones durante el interrogatorio son una manifestación del derecho de contradicción probatoria que garantiza que al juicio oral no lleguen pruebas ilegales, e impertinentes, y además permite que las partes controlen las actitudes indebidas de la parte contraria.

\section{Conclusiones}

¿Cómo se evidencia el principio de contradicción probatoria en la fase de juicio oral en el proceso penal colombiano?

En Colombia estamos en presencia de un Estado Social de Derecho, donde prevalece la Constitución Política del País y los Tratados Internacionales ratificados por el mismo, los cuales hacen parte del Bloque de Constitucionalidad y tienen prevalencia interna en la misma medida de la Carta Política, siempre que versen sobre derechos fundamentales, por tal razón nuestro Sistema Penal debe tener su base en los principios constitucionales y todas las actuaciones deben darse respetando la dignidad humana, la libertad, la igualdad y el debido proceso. La Corte Constitucional en Sentencia C 592 (2005) afirma "las normas del Código de Procedimiento Penal (ley 906 de 2004), deben comprenderse y aplicarse conforme a los derechos fundamentales y a los principios consagrados en la Constitución", además "el poder de contradicción, es decir, un aspecto central del derecho de defensa por parte del acusado, mantiene plenamente su status de garantía fundamental de la persona, y se materializa con la sujeción constitucional de la etapa de juzgamiento a los principios de oralidad y contradicción" (Sentencia C 592 de 2005)

En este sentido, se acoge la idea de que,

sobre el debido proceso es pertinente decir también que él, como idea ético-política, constituye un concepto largamente vinculado al sistema procesal penal acusatorio, que es decir, a una concepción tendencialmente democrática en el orden de los métodos de persecución penal y de las relaciones poder- individuo, relaciones que nunca son tan tensas como en el derecho penal y que, según como dialécticamente se articulen, definen, mejor que nadie, el grado de civilidad de una determinada organización socio-política (Calle, 2000, p.3).

En ese orden de ideas el descubrimiento probatorio está vinculado indisolublemente al debido proceso, al derecho a la defensa, y al derecho de contradicción en razón a la trascendental incidencia de dicho instituto en el desarrollo de la actividad de cada una de las partes. 
La contradicción en materia probatoria es un tema que tiene relevancia en todas las áreas del derecho, y en especial del derecho penal, de ahí que estudiar el mismo resulte interesante para la discusión académica, razón por la cual luego de lo esbozado hasta ahora y como aporte a la discusión se puede concluir que el derecho de contradicción probatoria en el juicio oral se evidencia:

En la oportunidad que tienen la partes de ser escuchadas, previo a la toma de decisiones que les afecte, decisiones que deberán ser tomadas de acuerdo a lo motivado, dentro de la relación dialéctica, de no ser así se vulneraria el derecho de defensa y consecuentemente el derecho de contradicción.

En la posibilidad que tiene la defensa para proponer objeciones al escrito de acusación presentado por la Fiscalía, si no reúne los requisitos establecidos en el artículo 337 de la ley 906 de 2004, para que el Fiscal lo aclare, adicione o corrija de inmediato.

En la posibilidad que tiene la defensa de pedir el descubrimiento de un elemento material probatorio especifico de que tenga conocimiento que la Fiscalía tiene en su poder.

En la posibilidad que tienen las partes de controvertir las pruebas frente a la otra parte en igualdad de condiciones. En el juicio oral la defensa está en posibilidad de ejercer las facultades que le han sido otorgadas por la misma ley para el recaudo, solicitud y contradicción de pruebas, sin ninguna limitante por parte de su contraparte, sino con las limitantes propias del Estado de Derecho, que exige que no se afecte a terceros ni se vulneren derechos fundamentales, control que le corresponde ejercer al juez de conocimiento.

En la posibilidad que tiene el procesado a través de su defensor de pronunciarse con respecto a la legalidad, licitud, admisibilidad, conducencia y pertinencia de cada uno de los medios que la Fiscalía pretenda introducir al juicio oral, además podrá pedir la exclusión o rechazo de un medio probatorio.

En la oportunidad de que se practiquen y valoren las pruebas en forma pública y con participación del procesado conforme a los principios de concentración, inmediación y contradicción de la prueba.

En la posibilidad de la contraparte de poder contrainterrogar a los testigos, y a través de dicho contrainterrogatorio desvirtuar o poner en duda lo dicho por estos.

En la posibilidad de presentar objeciones durante los interrogatorios a los testigos, siempre que quien interrogue viole las reglas para el interrogatorio.

En el nuevo sistema procesal penal con tendencia acusatoria, la etapa del juicio tiene preponderancia frente a la fase de investigación, por cuanto en ella se practicarán las pruebas que servirán de fundamento para la sentencia, por tal razón dicha etapa debe darse respetando los principios de inmediación, oralidad y en especial de contradicción probatoria, ya que este último es el eje fundamental para llevar al Juez convicción sobre la verdad de lo sucedido.

Finalmente es preciso manifestar que la única forma de que llegar a una sentencia justa, es respetando y garantizando el derecho de contradicción de las partes, quie- 
nes aún con intereses contrapuestos podrán interactuar en una relación de debate, dicho debate será pacifico en el marco del respeto a los preceptos constitucionales y legales, lo cual posibilitara que cada una de las partes realice el ejercicio de demostrar que tiene la razón, y así un tercero imparcial decida, de acuerdo a lo probado.

\section{Referencias}

Bernal, C. (2005). El derecho de los derechos: escrito sobre la aplicación de los derechos fundamentales. Bogotá, Colombia: Universidad Externado de Colombia. http:// www.marcialpons.es/libros/el-derecho-de-los-derechos/9789586169028/

Calle, A. (2000). Beses para una fundamentación político-constitucional del debido proceso. 3-28. http://publicaciones.eafit.edu.co/index.php/nuevo-foro-penal/ article/viewFile/3940/3210

Carneluitti, F. (1955). La Prueba Civil. Buenos Aires: Arayu. https://www.researchgate. net/publication/44545772_La_prueba_civil_Francesco_Carnelutti

Constitución de los Estados Unidos 'Enmienda XIV'. (9 de Julio de 1868). http://biblioteca.libertyfund.org/bibliotecadelalibertad/la-declaracion-de-independencia/ enmiendas

Constitución Política de Colombia. (1991). Bógota DC.: Legis. http://www.tiendalegis. com/Publicaciones/constitucion-politica-de-colombia.asp

Corte Constitucional de Colombia. (1992). Sentencia C- 406 . Ciro Angarita Baron Recuperado de http://www.corteconstitucional.gov.co/relatoria/1992/t-406-92. htm.

Corte Constitucional de Colombia. (5 de Febrero de 1996). Sentencia C-038. MP Eduardo Cifuentes Muñoz. Recuperado de http://www.corteconstitucional.gov.co/relatoria/1996/c-038-96.htm

Corte Constitucional de Colombia. (24 de Enero de 2001). Sentencia SU 062-01. MP Eduardo Montealegre. Recuperado de http://corteconstitucional.gov.co/relatoria/2001/SU062-01.htm

Corte Constitucional de Colombia. (18 de Julio de 2002). Sentencia T 553-02. MP Alfredo Beltran Sierra. Recuperado de http://www.corteconstitucional.gov.co/ relatoria/2002/T-553-02.htm

Corte Constitucional de Colombia. (9 de Junio de 2005). Sentencia C 591-05. MP Clara Ines Vargas Hernández. Recuperado de http://www.corteconstitucional.gov.co/ relatoria/2005/c-591-05.htm

Corte Constitucional de Colombia. (9 de Junio de 2005). Sentencia C 592-02. MP Alvaro Tafur Galvis. Recuperado de http://www.corteconstitucional.gov.co/relatoria/2005/c-592-05.htm

Corte Constitucional de Colombia. (3 de Julio de 2013). Sentencia C 402-13. MP Luis Ernesto Vargas Silva. Recuperado de http://www.corteconstitucional.gov.co/RELATORIA/2013/C-402-13.htm 
Corte Constitucional de Colombia, Sala plena. (12 de Enero de 1993). Sentencia T-1, Expediente T-3668. MP Jaime Sanín Greiff enstein. Recuperado de http://www. corteconstitucional.gov.co/relatoria/1993/T-001-93.htm

Corte Suprema de Justicia. (2007). Sala de Casación Penal. Sentencia 26468. Recuperado http://legal.legis.com.co/document?obra=jurcol\&document=jurcol 759920423b54f034e0430a010151f034

Corte Suprema de Justicia, Sala de Casación Penal. (11 de Junio de 2014). Auto AP31362014. MP Maria del Rosario Gonzáles Muñoz. Recuperado de cispa.gov.co/index.php

Declaración Universal de Derechos del Hombre. (10 de Diciembre de 1948). Articulo 10. http://www.un.org/es/universal

Declaración Universal de los Derechos Humanos. (10 de Diciembre de 1948). Articulo 11. http://www.un.org/es/universal

Devis, H. (2012). Teoria General de la Prueba Judicial. Colombia: Editorial Temis. https://es.slideshare.net/rubenradaescobar/

Hoyos, A. (1993). El debido proceso. Bogotá, Colombia: Editorial Temis SA.

Iguarán, M. (2006). 100 Pregruntas Sistema Penal Acusatorio. 1-20. http://biblioteca. cejamericas.org/bitstream/handle/2015/4786/10preguntasprocesopenal.pdf? sequence $=1$ \&isAllowed $=y$

Ramírez, M. (19 Enero-Junio 2007). La problemática de Definir la Juridicción. Revista Internauta de Práctica Jurídica, 25. http://www.libreriadelau.com/

Ramírez, M. (2005). El Debido Proceso. http://revistas.udem.edu.co/index.php/opinion/article/view/1307/1283

Ramirez, M. (Enero-Junio de 2007). La problemática de Definir la Jurisdicción. Revista Internauta de Práctica Jurídica(19), 1-25. https://www.uv.es/ajv/art jcos/ art jcos/num19/RIPJ 19/EX/19-9.pdf

República, C. d. (1991). Constitución Política de Colombia. Bógota DC. http://www.alcaldiabogota.gov.co/sisjur/normas/Norma1.jsp?i=4125

Ruiz, L. B. (7 de Marzo de 2007). El Derecho a la Prueba Como un Derecho Fundamental, Estudios de Derechos. Estudios de Derechos, 1-26. https://aprendeenlinea.udea.edu.co/revistas/index.php/red/article/view/2552

Ruiz , L. B. (s.f). Los principios del derecho probatorio. Colombia.

Valencia, A. (1988). Desarrollo del Constitucionalismo (Segunda edición ed.). La paz, Bolivia: Juventud.

Velloso, A. A. (2002). Origen del Proceso. Buenos Aires, Argentina: Rubinzal-Culzoni. http://docenteflorez.webnode.es/products/Sin nos ad eturerr oratia cum volores ellatianis aligenis adis mint facepe nobisimus anto veles rehenisi re id quodi ommodipsam eiciam qui sit et unt offic tem dia sundaec testem sunt am 